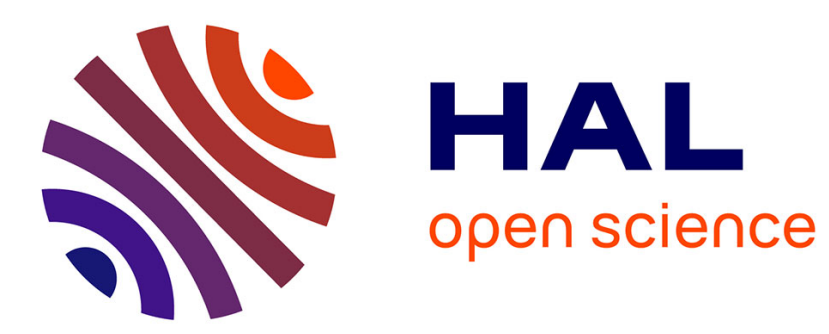

\title{
Bottom-up Generation of Miniaturized Coaxial Double Electrodes with Tunable Porosity
}

Aleksandar Karajic, Stéphane Reculusa, Matthias Heim, Patrick Garrigue, Serge Ravaine, Nicolas Mano, Alexander Kuhn

\section{- To cite this version:}

Aleksandar Karajic, Stéphane Reculusa, Matthias Heim, Patrick Garrigue, Serge Ravaine, et al.. Bottom-up Generation of Miniaturized Coaxial Double Electrodes with Tunable Porosity. Advanced Materials Interfaces, 2015, 2 (1500192), pp.1-5. 10.1002/admi.201500192 . hal-01187110

\author{
HAL Id: hal-01187110 \\ https://hal.science/hal-01187110
}

Submitted on 2 Oct 2017

HAL is a multi-disciplinary open access archive for the deposit and dissemination of scientific research documents, whether they are published or not. The documents may come from teaching and research institutions in France or abroad, or from public or private research centers.
L'archive ouverte pluridisciplinaire HAL, est destinée au dépôt et à la diffusion de documents scientifiques de niveau recherche, publiés ou non, émanant des établissements d'enseignement et de recherche français ou étrangers, des laboratoires publics ou privés. 


\title{
Bottom-up Generation of Miniaturized Coaxial Double Electrodes with Tunable Porosity
}

\author{
Aleksandar Karajic, Stéphane Reculusa, Matthias Heim, Patrick Garrigue, Serge Ravaine, \\ Nicolas Mano, and Alexander Kuhn
}

The demand for miniaturized and eventually implantable electrochemical tools such as biosensors, biofuel cells, and batteries has led to the development of new technologies to overcome existing problems related to large dimensions, low current densities, and insufficient power output of such devices. ${ }^{[1-3]}$ In the past decade, controlled tailoring the surface properties of electrodes has been explored in order to increase their active surface area and thus improve those key performances. For the design of electrode surfaces, self-assembly, and electrodeposition processes can be used to create a wide range of structures, well-adapted to the performance and functionality of such systems. Well-organized self-assembled structures of silica, ${ }^{[4,5]}$ polystyrene, ${ }^{[6,7]}$ latex, ${ }^{[8]}$ and poly(methylmethacrylate) (PMMA) ${ }^{[9]}$ particles have been used for more than a decade as excellent templates for the fabrication of porous electrodes based on the electrodeposition of conducting polymers, metals, and semiconductors. ${ }^{[10-18]}$ The so-obtained porous materials are perfect candidates for the design of miniaturized devices. ${ }^{[19-23]}$

As has been pointed out previously, such approaches are crucial for developing high-performance microelectrodes, able to ensure, for example, high-power density without sacrificing energy density by combining small ion diffusion distances, large percentage of active material, and highly conductive electrodes. ${ }^{[3]}$

Due to the enhanced active surface area, it is possible to decrease the overall geometric dimensions of the device without decreasing the current, or to improve the current while maintaining the geometric surface area.

Moreover, by choosing an architecture with a cylindrical geometry, it should be possible to improve the mass transport of electroactive species toward the electrode surface, ${ }^{[24]}$ which is one of the essential problems to solve in order to elaborate

A. Karajić, Dr. S. Reculusa, Dr. M. Heim,

P. Garrigue, Prof. A. Kuhn

Univ. Bordeaux, UMR 5255

CNRS, Bordeaux INP

ENSCBP

16 Avenue Pey Berland, 33607 Pessac, France

E-mail: kuhn@enscbp.fr

Dr. S. Reculusa

BrivaTech - ADERA

ENSCBP

16 Avenue Pey Berland, 33607 Pessac, France

Prof. S. Ravaine, Dr. N. Mano

Univ. Bordeaux Centre de Recherche Paul Pascal

UPR 8641, CNRS

Avenue Albert Schweitzer

33600 Pessac, France efficient electrochemical devices, particularly in the field of implantable biofuel cells and biosensors. Among other parameters, the diffusion and redox reaction of molecules such as oxygen determines the operating voltage and thus the efficiency of oxygen-dependent biofuel cells. ${ }^{[25,26]}$

The present work introduces a new and straightforward strategy for the bottom-up fabrication of a miniaturized coaxial electrode architecture based on highly organized porous gold as a structural material with controllable thickness and pore diameter. Preliminary experiments were carried out with goldcoated glass slides and, subsequently, gold microwires served as substrates for the deposition of silica particles using the Langmuir-Blodgett (LB) technique to form a colloidal crystal on their surface.

These silica opals were filled by electrodeposition with alternating metal layers in order to obtain a final porous structure with two independently addressable macroporous gold electrodes. They constitute an extremely miniaturized and fully integrated electrochemical cell of either planar or cylindrical geometry with a characteristic active volume in the range of $0.1 \mu \mathrm{L}$, which can be further decreased if needed. Due to the controllable porosity and thickness of the electrode materials the approach that we present here opens a new path for the fabrication of electrochemical cells combining a significantly decreased footprint with an increase in active surface area.

The LB technique has been used for a long time for the controllable deposition of amphiphilic molecules or nanoparticles from a water-air interface onto the surface of a substrate. ${ }^{[27-31]}$ It presents a very convenient approach to form homogeneous and well-organized colloidal crystals, which is complementary to other techniques that have been used such as controlled evaporation, electrophoretic deposition, and dip coating. ${ }^{[32]}$ After dispersing the nanoparticles at the water-air interface of the LB trough, the compression of the film is followed by measuring the surface tension as a function of film area. The quality of the compression can be illustrated by depositing a defined number of silica particle layers on a solid substrate (Figure 1a).

The so-obtained colloidal crystal is used as a template during a subsequent electrodeposition step. In order to obtain the final miniaturized two electrode electrochemical cell, alternating gold-nickel-gold metal layers were generated in the colloidal crystal template, with the nickel layer playing the role of a sacrificial spacer between the two gold layers (Figure 1b). In a first set of experiments, a flat gold substrate coated with multilayers of silica particles was used for the successive electrodeposition of gold, nickel, and gold under potentiostatic conditions. After dissolving the intermediate nickel layer (Figure 1c), the structure is stabilized by incorporating a small amount of nail varnish at the extremities of the sandwich-type structure (in the 


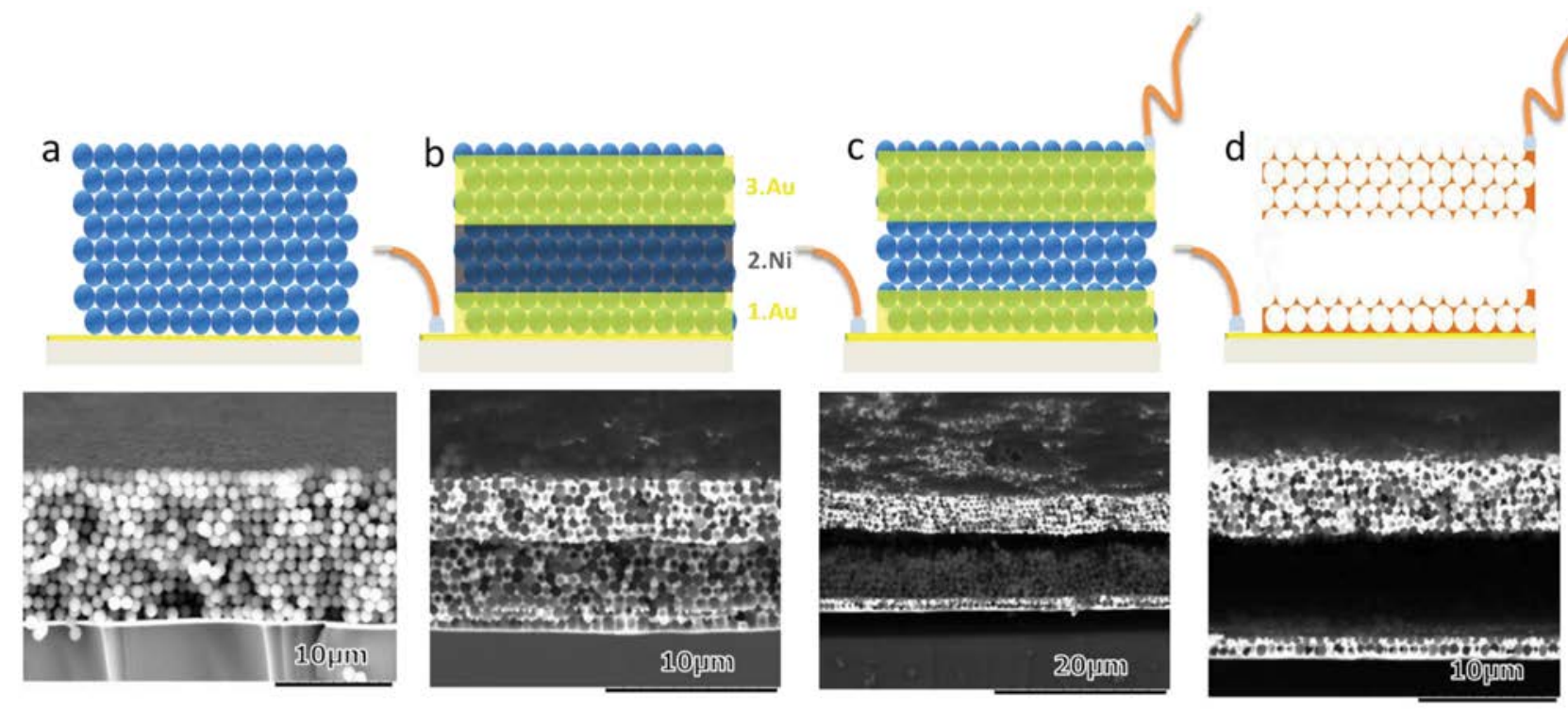

Figure 1. Schematic representation showing the different steps of the fabrication of the miniaturized two electrode electrochemical cell (first row) with the corresponding cross sectional SEM images (second row). a) Assembly of a colloidal template made of silica beads on a gold-coated glass slide (12 layers of $1 \mu \mathrm{m}$ diameter particles), b) composite metal-silica structure obtained after electrodeposition of sequential gold, nickel, and gold layers in a template consisting of $740 \mathrm{~nm}$ silica beads, c) intermediate structure obtained after selective dissolution of the nickel layer, and d) final two electrode device with controlled electrode spacing in the micrometer range obtained after dissolution of the silica template.

present case on the left and right side of the structure shown in Figure 1c). This strategy is used in order to block mechanically the two porous gold electrodes after the dissolution of the sacrificial nickel layer. If there were no nail varnish at the extremities of the coaxial device, the two separated electrodes would collapse one onto the other. The composition of the varnish is not really important as any other polymer that allows mechanical stabilization of the electrode architecture is equally useable. The important point is that the polymer needs to be an electric insulator in order not to cause an electric short circuit between the two electrodes.

To address each macroporous gold electrode separately, two electrical connections were established; the first one on the bottom gold slide, which is in direct contact with the first macroporous gold electrode (Figure 1b), and the second one on the surface of the upper macroporous gold electrode (Figure 1c). In a final step, the silica beads were dissolved with diluted hydrofluoric acid (Figure 1d). The originality of the approach resides in the fact that the potentiostatic reduction of the metal ions allows a perfect control over the thickness, and thus the number of pore layers, as well as the spacing between the two individual electrodes. This is due to the fact that the current measured as a function of time shows regular oscillations in intensity. These oscillations are intrinsically related to the periodically varying electroactive surface when the metal growth front is penetrating into the colloidal crystal starting from the bottom. One full period of oscillation corresponds to the penetration of one monolayer of beads. It is therefore possible to stop the deposition at will at a given position with very high precision. (Figure 2a.)

In the cross sectional scanning electron microscopy (SEM) image of the final metal architecture (Figure 2b), macroporous gold and nickel appear in white and light-gray colors, respectively. The SEM image illustrates the good structural organization and the uniformity of the system with homogeneously distributed pores.

To verify the structural integrity once the sacrificial nickel layer has been removed, the two individual porous gold electrodes (electrodes A and B in Figure 3a) have been studied by cyclic voltammetry and their active surface was measured based on the integral of the stripping peak corresponding to the reduction of interfacial gold oxide (peak around $+0.9 \mathrm{~V}$ in Figure $3 \mathrm{~b}$ ). A device with two electrodes with very different active surface areas has been chosen on purpose to make their stripping signal easily distinguishable and to demonstrate the versatility of the modification. As shown in Figure 3b, electrode

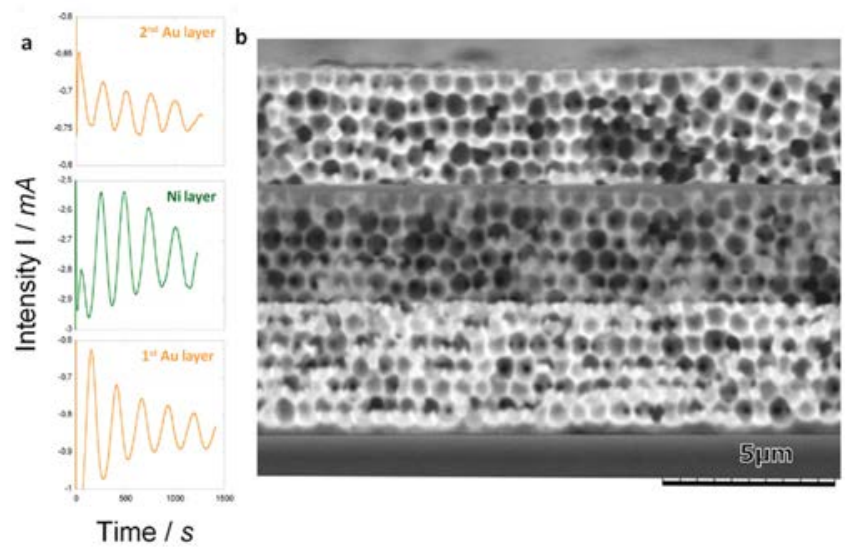

Figure 2. a) Chronoamperometric curves for the alternating electrodeposition of gold (11 half-layers), nickel ( 10 half-layers), gold ( 10 half-layers) layers. b) Cross sectional images of the final porous metal structure with a pore diameter of $600 \mathrm{~nm}$. 
a

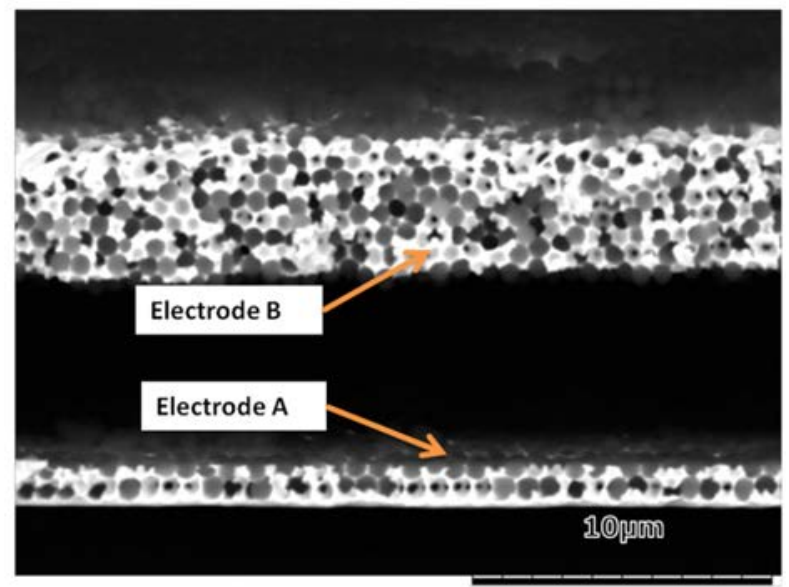

b

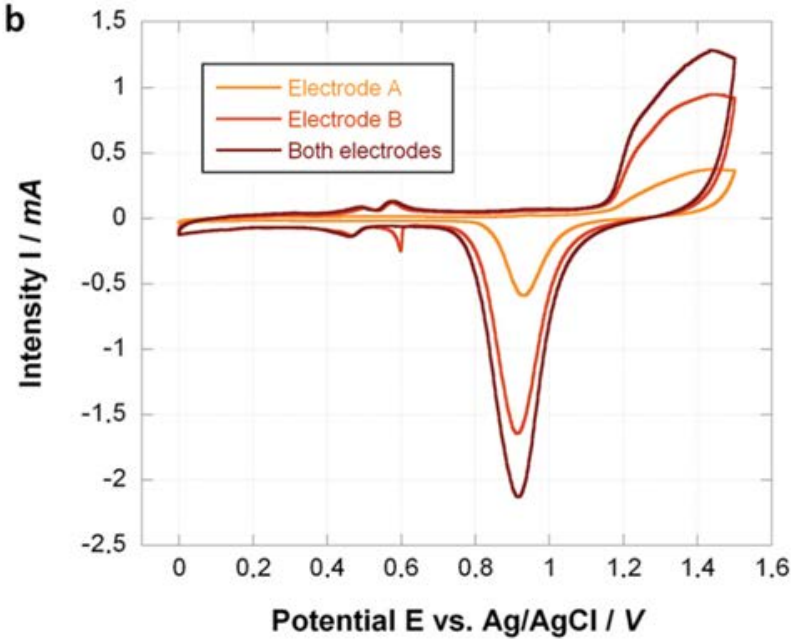

Figure 3. a) Cross sectional SEM picture showing a porous structure after the dissolution of nickel with sulfuric acid b) cyclic voltammetry (CV) stripping curves (recorded at $25^{\circ} \mathrm{C}$, scan rate: $100 \mathrm{mV} \mathrm{s}^{-1}$ in $0.5 \mathrm{~m}$ sulfuric acid solution) of macroporous gold electrodes deposited on a single support and separated by an electrolyte gap. Electrode A corresponds to the lower electrode ( 3 half-layers of $600 \mathrm{~nm}$ macroporous gold) and electrode $B$ to the upper one (10 half-layers of $600 \mathrm{~nm}$ macroporous gold). Electrode $B$ shows a small signal from 0.4 to $0.6 \mathrm{~V}$, corresponding to the electrochemical reaction of traces of silver paint used for connecting the outer electrode.

B shows a much bigger stripping signal (corresponding to $\left.6.2 \mathrm{~cm}^{2}\right)$ compared to the electrode $\mathrm{A}\left(2.0 \mathrm{~cm}^{2}\right)$. The ratio of the active surface areas $\left(\left[\mathrm{S}_{\text {(top) }} / \mathrm{S}_{\text {(bottom) }}\right]=3.1\right)$ is in a good agreement with the ratio of silica bead layers infiltrated with gold $\left(\left[\mathrm{N}_{\text {(top) }} / \mathrm{N}_{\text {(bottom) }}\right]=3.3\right)$. In a control experiment, both electrodes were externally short-circuited and their common surface was determined to be $8.8 \mathrm{~cm}^{2}$, which is in good agreement with the sum of the two individual electrodes, having in mind that the accuracy of surface determination is in the range of $\pm 10 \%$. This proves that the macroporous electrodes A and B are not interconnected and thus are independently addressable. In addition we have verified the electrical independence of the two electrodes by measuring the Ohmic resistance between them. The obtained values in the $\mathrm{M} \Omega$ range confirm the absence of an electrical short circuit. The spacing between the two electrodes

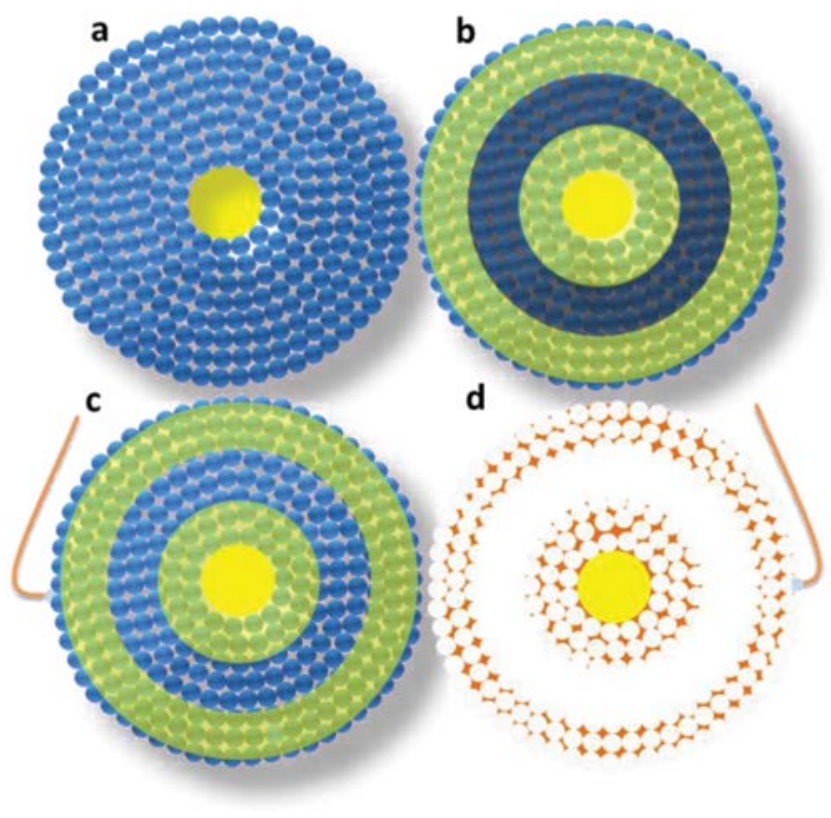

Figure 4. Schematic representation in cross-sectional view of the key steps for the elaboration of a miniaturized coaxial two-electrode electrochemical cell: steps a-d) are identical to those in Figure 1, with the difference that the initial substrate is a gold wire (represented as a yellow disk at the centre) instead of a flat surface.

in this specific case is $10 \mu \mathrm{m}$, but smaller gaps can also be generated when a thinner sacrificial nickel layer is used.

After these proof-of-principle experiments on a flat substrate, we explored the possibility to transpose the present concept to cylindrical substrates for the design of efficient electrochemical devices. As illustrated in Figure 4 we performed electrodeposition of the same metals through a cylindrical multilayered LB film, ${ }^{[33-35]}$ with $\mathrm{SiO}_{2}$ particles of $600 \mathrm{~nm}$ deposited onto the surface of gold microwires ( $250 \mu \mathrm{m}$ diameter).

As previously shown for the samples with planar geometry, we again observed in this case well-pronounced oscillations for the cylindrical substrate during the electrodeposition (Figure 5).

In the final electrode architecture, metal layers with a very homogeneous thickness around the wire can be observed (Figure 6a). After nickel is removed by electrochemical etching under acidic conditions, a regular and well defined gap is created between the two porous gold layers (Figure $6 \mathrm{~b}, \mathrm{c}$ ). The size of the gap can be precisely tuned from several tens of
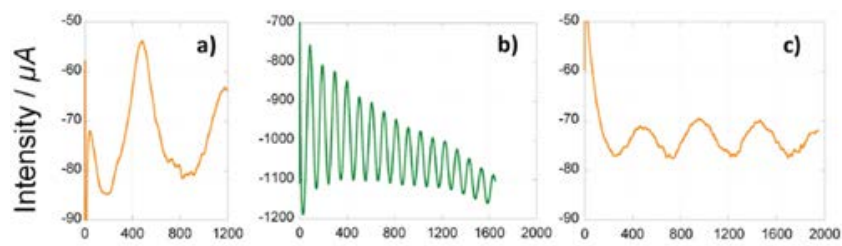

Time/s

Figure 5. Chronoamperometric curves recorded during the electrodeposition of alternating macroporous a) gold ( 3 half-layers), b) nickel (32 half-layers), and c) gold ( 8 half-layers) layers into the cylindrical colloidal template. 

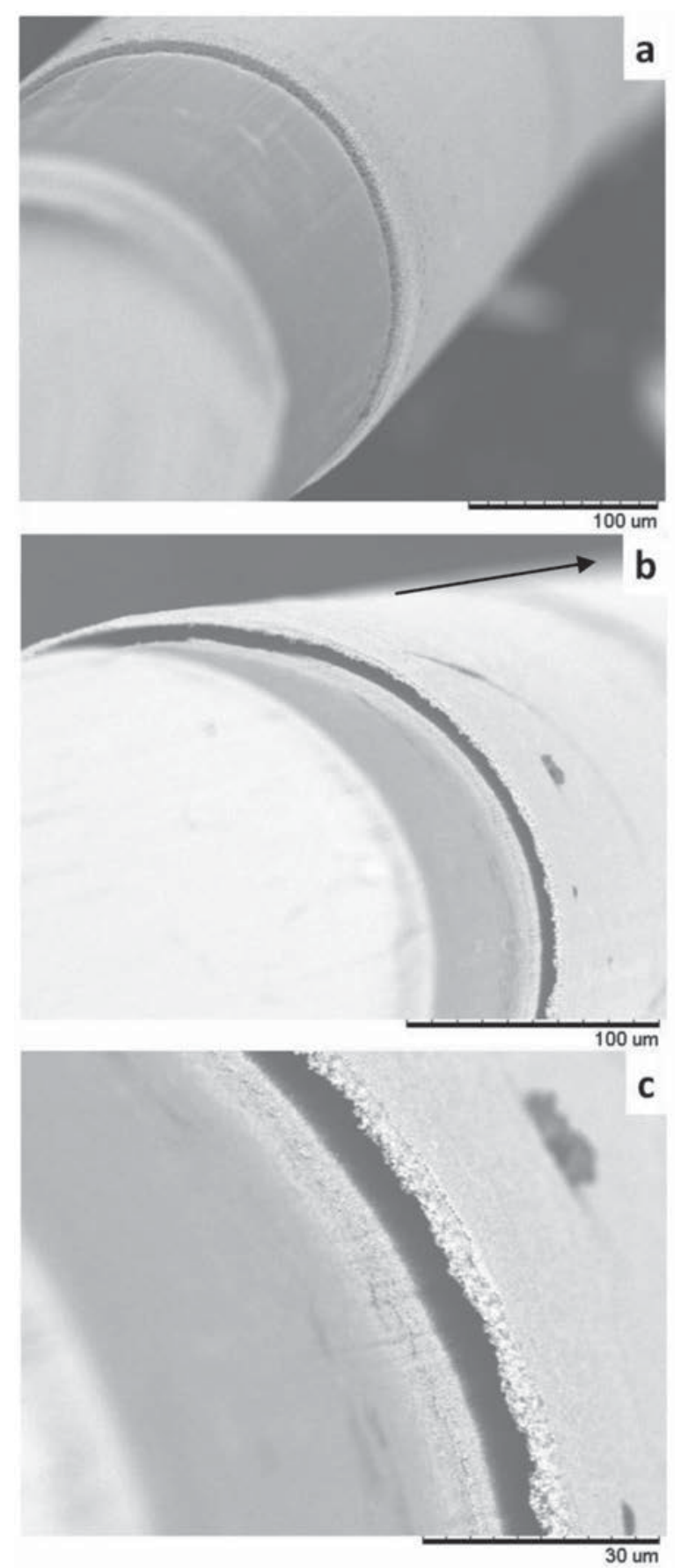

Figure 6. SEM characterization of the coaxial two-electrode electrochemical cell before a) and after b,c) electrochemical etching carried out at $1.5 \mathrm{~V}$ in $30 \% \mathrm{H}_{2} \mathrm{SO}_{4}$ over $60 \mathrm{~min}$. The black arrow in picture (b) indicates the direction where a structure-stabilizing varnish spot is located.

nanometers to several microns depending on the thickness of the sacrificial nickel layer.

This allows adjusting the distance between the two active electrodes as a function of the experimental requirements in terms of desired transport properties in the electrolyte gap.

Cyclic voltammetry clearly demonstrates once again the electrical independence of both cylindrical electrodes and thus the

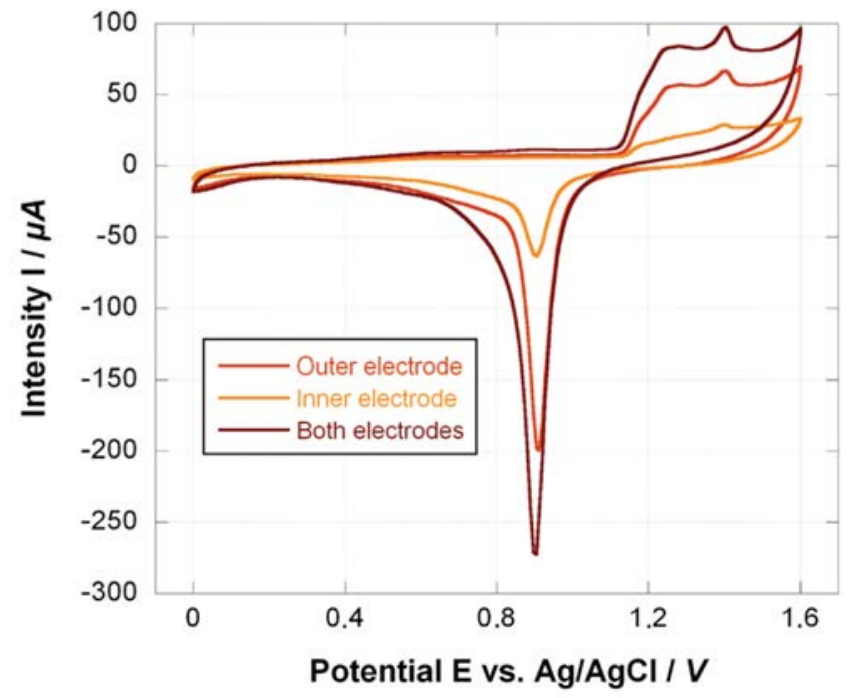

Figure 7. Electrochemical characterization of structural stability and electrical independence of the coaxial electrodes once the silica beads are removed from the structure. The corresponding active surfaces of the independent coaxial electrodes and of the short-circuited system were $0.26,0.62$, and $0.93 \mathrm{~cm}^{2}$, respectively. CVs have been recorded at ambient temperature, at a scan rate of $100 \mathrm{mV} \mathrm{s}^{-1}$ in $0.5 \mathrm{M}$ sulfuric acid solution.

structural stability of the device (Figure 7). Even after more than one hundred potential cycles no changes in these signals are observed, meaning that the two electrodes still act as independent devices without short-circuit and that they do not undergo structural changes or degradation.

To evaluate the electrochemical functionality of such a combined system with respect to redox reactions of species present in solution, it is crucial to test whether those species are able to reach the inner electrode by diffusion without difficulties. Indeed, the miniaturized, coaxial, and macroporous electrochemical cell presented here is a fully integrated system for which one could expect some mass-transport limitations for the inner electrode, due to the presence of the outer electrode. The outer electrode should not experience any problems of this kind due to its direct contact with the bulk solution. However, in order to reach the inner electrode, electroactive species present in the electrolyte solution need to penetrate the outer cylindrical macroporous electrode and diffuse through the internal volume of the cell (determined by the spatial separation between the coaxial electrodes). Reduction of oxygen has been used as a key test to validate the system due to the low solubility/diffusivity of oxygen in liquids and because of the importance of oxygen reduction in electrochemical devices such as (bio)fuel cells. Figure 8 presents the reduction currents for oxygen in saturated $50 \times 10^{-3} \mathrm{M}$ sulfuric acid. A difference in current is measured when the coaxial electrodes are connected separately, compared to the situation when they are short-circuited (Figure 8). A slight shift in onset potentials toward more positive values is also observed for the electrodes with higher surface areas, which is due to a magnifying effect of the higher currents (inset Figure 8).

In conclusion, a miniaturized electrochemical cell, integrating two macroporous electrodes with planar or cylindrical 


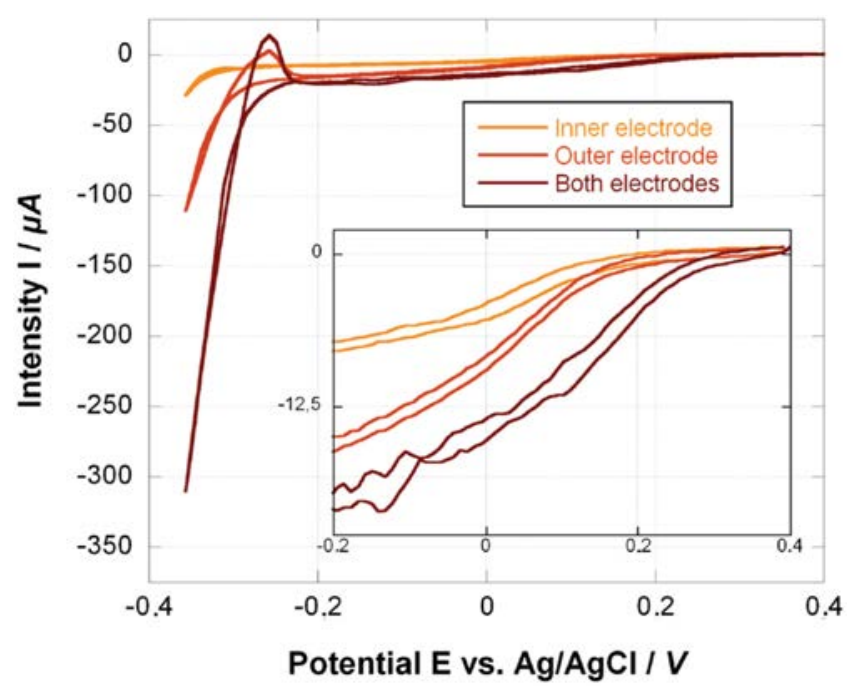

Figure 8. Cyclic voltammograms of the oxygen reduction recorded in oxygen saturated $50 \times 10^{-3} \mathrm{M}$ sulfuric acid at room temperature at a scan rate of $5 \mathrm{mV} \mathrm{s}^{-1}$. The coaxial electrodes were prepared by electrochemical deposition of gold ( 3 half-layers-inner electrode, 10 half-layers-outer electrode) into the silica based colloidal crystal template. The two electrodes are separated by a $14 \mu \mathrm{m}$ gap.

geometry, has been elaborated by a bottom-up process based on template electrodeposition. Colloidal crystals composed of silica beads and obtained by the Langmuir-Blodgett technique were used as templates. The template-covered gold substrates were directly used for the electrodeposition of alternating goldnickel-gold metal layers under potentiostatic conditions. Well pronounced oscillations in current intensity allowed the precise control of the electrodeposition process. This enabled the finetuning of (a) the number of pore layers for each individual electrode, (b) the pore size as well as (c) the gap between the two porous electrodes.

Structural stability was demonstrated by cyclic voltammetry in acidic medium. It was shown that each electrode can be individually addressed and that redox species dissolved in the solution can easily reach the outer and, most importantly, also the inner electrode without experiencing major transport problems.

The presented structure is the first example of a fully integrated miniaturized coaxial electrochemical cell with performance-enhancing macroporous electrodes. Such architectures with a versatile design principle are potentially suitable for the elaboration of implantable biofuel cells and/or biosensors. They combine an artificially increased active surface area with an improved mass transport due to the radial diffusion in the case of a cell with coaxial geometry. These features can lead to current densities that are one or two orders of magnitude higher compared to conventional electrodes, ${ }^{[3,35,36]}$ which ultimately should lead to higher power output when such electrodes are used in energy conversion systems. Work in this direction is currently in progress.

\section{Supporting Information}

Supporting information is available from the Wiley Online Library or from the author.

\section{Acknowledgements}

This work, realized within the framework of the Laboratory of Excellence AMADEus with the reference ANR-10-LABX-0042-AMADEUS, has benefitted from aid by the state operated "Agence Nationale de la Recherche" under the program "Initiative for Excellence IdEx Bordeaux" holding the reference ANR-10-IDEX-0003-02. The work has also been partially supported by the European project Bioenergy (FP7-PEOPLE-2013-ITN 607793).

[1] M. Cadet, X. Brilland, S. Gounel, F. Louerat, N. Mano, ChemPhysChem 2013, 14, 2097.

[2] I. Willner, Y. Yan, B. Willner, R. Tel-Vered, Fuel Cells 2009, 9, 7.

[3] J. H. Pikul, H. Gang Zhang, J. Cho, P. V. Braun, W. P. King, Nat. Commun. 2013, 4, 1732.

[4] S. Reculusa, S. Ravaine, Chem. Mater. 2003, 15, 598.

[5] O. D. Velev, T. A. Jede, R. F. Lobo, A. M. Lenhoff, Chem. Mater. 1998, 10, 3597.

[6] Y. Fu, Z. Jin, Z. Liu, Y. Liu, W. Li, Mater. Lett. 2008, 62, 4286.

[7] Z. Liu, J. Ya, Y. Xin, J. Ma, C. Zhou, J. Cryst. Growth 2006, $297,223$.

[8] W. Han, M. Byun, Z. Lin, J. Mater. Chem. 2011, 21, 16968.

[9] H. Yan, C. F. Blanford, W. H. Smyrl, A. Stein, Chem. Commun. 2000, 1477.

[10] T. Sumida, Y. Wada, T. Kitamura, S. Yanagida, Chem. Commun. 2000, 1613.

[11] A. Stein, R. C. Schroden, Curr. Opin. Solid State Mater. Sci. 2001, 5, 553.

[12] P. V. Braun, P. Wiltzius, Curr. Opin. Colloid Interface Sci. 2002, 7, 116.

[13] Y.-C. Lee, T.-J. Kuo, C.-J. Hsu, Y.-W. Su, C.-C. Chen, Langmuir 2002, 18, 9942.

[14] C. Li, H. Bai, G. Shi, Chem. Soc. Rev. 2009, 38, 2397.

[15] P. N. Bartlett, M. A. Ghanem, I. S. El Hallag, P. de Groot, A. Zhukov, J. Mater. Chem. 2003, 13, 2596.

[16] P. N. Bartlett, J. J. Baumberg, P. R. Birkin, M. A. Ghanem, M. C. Netti, Chem. Mater. 2002, 14, 2199.

[17] P. N. Bartlett, P. R. Birkin, M. A. Ghanem, C.-S. Toh, J. Mater. Chem. 2001, 11, 849.

[18] H. Ning, A. Mihi, J. B. Geddes III, M. Miyake, P. V. Braun, Adv. Mater. 2012, 24, OP153.

[19] A. Walcarius, Anal. Bioanal. Chem. 2010, 396, 261.

[20] R. Szamocki, A. Velichko, C. Holzapfel, F. Mücklich, S. Ravaine, P. Garrigue, N. Sojic, R. Hempelmann, A. Kuhn, Anal. Chem. 2006, 79, 533.

[21] A. Heller, Phys. Chem. Chem. Phys. 2004, 6, 209.

[22] A. Heller, Anal. Bioanal. Chem. 2006, 385, 469.

[23] A. Heller, AlChE J. 2005, 51, 1054.

[24] F. Gao, L. Viry, M. Maugey, P. Poulin, N. Mano, Nat. Commun. 2010, 1, 2.

[25] N. Mano, J. L. Fernandez, Y. Kim, W. Shin, A. J. Bard, A. Heller, J. Am. Chem. Soc. 2003, 125, 15290.

[26] G. T. R. Palmore, H.-H. Kim, J. Electroanal. Chem. 1999, 464, 110.

[27] K. B. Blodgett, J. Am. Chem. Soc. 1935, 57, 1007.

[28] P. Massé, S. Reculusa, S. Ravaine, Colloids Surf., A 2006, 284, 229.

[29] P. Massé, S. Ravaine, Colloids Surf., A 2005, 270, 148.

[30] S. Reculusa, S. Ravaine, Appl. Surf. Sci. 2005, 246, 409.

[31] S. Reculusa, P. Massé, S. Ravaine, J. Colloid Interface Sci. 2004, 279, 471.

[32] X. Ye, L. Qi, Nano Today 2011, 6, 608.

[33] M. Heim, S. Reculusa, S. Ravaine, A. Kuhn, Adv. Funct. Mater. 2012, 22, 538.

[34] N. Mano, A. Kuhn, S. Ravaine, M. Heim, S. Reculusa, Eur. Patent EP 14306341.02014.

[35] S. Reculusa, M. Heim, F. Gao, N. Mano, S. Ravaine, A. Kuhn, Adv. Funct. Mater. 2011, 21, 691.

[36] M. Heim, C. Wattanakit, S. Reculusa, C. Warakulwit, J. Limtrakul, S. Ravaine, A. Kuhn, Electroanalysis 2013, 25, 888. 